\title{
FORMAÇÃO INICIAL DE PROFESSORES DE LIBRAS: PRIMEIROS DESAFIOS AO RECONHECIMENTO DO SUJEITO MULTIFACETADO
}

\author{
INITIAL EDUCATION FOR LIBRAS TEACHERS: FIRST CHALLENGES ON THE RECOGNITION OF A \\ MULTIFACETED SUBJECT \\ FORMACIÓN INICIAL DE PROFESORES DE LIBRAS: LOS PRIMEROS DESAFÍOS AL RECONOCIMIENTO DEL \\ SUJETO MULTIFACÉTICO
}

\author{
KUMADA, Kate Mamhy Oliveira ${ }^{1}$ \\ PRIETO, Rosângela Gavioli2
}

\section{RESUMO}

As instituições federais de educação que ofertam cursos superiores para formação docente em Libras devem obediência à Lei $n^{\circ}$ 12.711/12 e ao Decreto $n^{\circ} 5.626 / 05$, concernente às políticas de ação afirmativa que contemplam, respectivamente, os grupos de pessoas egressas de escolas públicas e o grupo de pessoas surdas. Considerando que em nossa sociedade contemporânea o sujeito é constituído por múltiplas e fragmentadas identidades, cumpre questionar como as instituições federais se organizaram nessa empreitada diante da pluralidade de identidades de um único participante. Para isso, o presente artigo tem como objetivo investigar a efetivação do direito à prioridade atribuída aos surdos para ingresso em cursos de graduação destinados à formação de professores de Libras. Os resultados evidenciaram baixa adesão dessas instituições ao cumprimento da prioridade no acesso aos surdos, bem como o desafio por parte de algumas em lidar com o sujeito pós-moderno constituído por diferentes identidades. Palavras-chave: Identidades. Surdos. Educação superior. Formação de professores.

\section{ABSTRACT}

The federal education institutions that offer higher education for Libras teachers must comply with the Law 12,711/12 and the Decree No. 5,626 / 05, regarding affirmative action policies that include, respectively, the groups of people graduating from public schools and the group of deaf people. Considering that in our contemporary society the subject is constituted by multiple fragmented identities, it is important to verify how federal institutions are organized for this undertaking, in face of the plurality of identities of one single participant. For this purpose, this article aims to investigate the effectiveness of the right to priority attributed to deaf people when entering under graduation courses for Libras teacher formation. The results revealed a low adherence of these institutions to the fulfillment of the priority in the access to the deaf person, as well as the challenge of some to deal with the postmodern subject constitution determined by different identities.

Keywords: Identities. Deaf. Higher education. Teacher education.

\section{RESUMEN}

Las instituciones federales de educación que ofertan cursos superiores de formación docente en Lengua Brasileña de Señales (Libras), están subordinadas a la ley No 12.711/12 y al Decreto No 5.626/05, concerniente a las políticas de acción afirmativa que contemplan, respectivamente, a los grupos de personas egresadas de escuelas públicas y a los grupos de personas sordas. Considerando que en nuestra sociedad contemporánea el sujeto es constituido por múltiples y fragmentadas identidades, cumple cuestionar como las instituciones federales se organizaron en esta espartería delante de la pluralidad de identidades de un único participante. Para eso, el presente artículo tiene como objetivo investigar el efectivo derecho a la prioridad que se le atribuyó a la persona sorda para el ingreso en los cursos de graduación destinados a la formación de profesores de Libras. Los resultados demostraron que esas instituciones tienen poca adhesión hacia el cumplimiento de la prioridad en el acceso a las personas sordas, así como el desafío, por parte de algunas, en lidiar con el sujeto posmoderno constituido por diferentes identidades.

Palabras clave: Identidades. Sordos. Educación superior. Formación de profesores.

\footnotetext{
1 Universidade Federal do ABC - UFABC - São Paulo - Brasil

2 Universidade de São Paulo - USP - São Paulo - Brasil
} 


\section{INTRODUÇÃO}

Atualmente, estudiosos de diferentes áreas discutem os efeitos do advento da globalização sobre os aspectos culturais e linguísticos da sociedade contemporânea. Segundo Kumaravadivelu (2006), a organização social é influenciada pela globalização ao reduzir a distância espacial e temporal entre as pessoas, bem como ao contribuir para o desaparecimento de fronteiras. Nesse caso, não se trata especificamente de fronteiras geográficas baseadas no território, nem apenas de fronteiras nacionais em termos de comércio, capital e informação, mas que incluem valores e culturas. Dessa "porosidade das fronteiras" (FANTINI, 2004) emerge o que Canclini (2003, p. XIX) denomina de "culturas híbridas", entendendo a hibridação como "[...] processos socioculturais nos quais estruturas ou práticas discretas, que existiam de forma separada, se combinam para gerar novas estruturas, objetos e práticas.".

Por sua vez, dessa sociedade globalizada, organizada sob as novas relações de espaço, tempo e fronteiras, deriva o sujeito pós-moderno, que não tem mais uma identidade unificada e estável, senão várias identidades contraditórias e, possivelmente, provisórias (HALL, 1998). Para Woodward (2000, p. 31), isso decorre da emergência de novos papéis e identificações sociais que "[...] a complexidade da vida moderna exige que assumamos [...]", provocando assim, segundo a autora, a "crise de identidades".

Nessa direção, cumpre destacar que os sujeitos socialmente excluídos não podem ser vistos como um grupo homogêneo, pois em inúmeras situações congregam desvantagens sociais de várias ordens, tais como: econômica, cultural, política e outras (BONETI, 2006). Barnes (2010), por exemplo, enfatiza que a pobreza está frequentemente atrelada à deficiência, pois fatores como desnutrição, falta de saneamento básico e condições de trabalho precárias corroboram o aumento da sua incidência entre a população mais carente.

Sob esse cenário, cabe à educação o desafio de acolher os grupos de pessoas que se encontram de alguma forma discriminados e à margem da sociedade, como também a necessidade de considerar a constituição identitária plural e multifacetada desses sujeitos. Para sua efetivação, o Brasil adota ações afirmativas como orientação de políticas educacionais.

Segundo Goularte (2014), a expressão "ação afirmativa” surgiu inicialmente na década de 1980 no Brasil e incorporava não apenas os negros e as minorias étnicas e raciais, como também mulheres e pessoas com deficiência. A luta, de acordo com a autora, concentrou-se na busca da ampliação do ingresso dessas pessoas tanto no mercado de trabalho como no sistema educacional, especialmente na educação superior.

Sabe-se que no campo da educação de surdos, além da conquista pelo reconhecimento linguístico da Língua Brasileira de Sinais (Libras), alcançado por meio da Lei no 10.436 (BRASIL, 2002), a luta das comunidades surdas sempre esteve associada a uma escola bilíngue com a presença de professores surdos (QUADROS, 2006). Essa reivindicação integra, por exemplo, a pauta do 
documento intitulado "A educação que nós surdos queremos" (FEDERAÇÃO NACIONAL DE EDUCAÇÃO E INTEGRAÇÃO DOS SURDOS, 1999), por compreender a importância desse profissional na construção da identidade surda, ou seja, para a identificação desses sujeitos com um grupo de pertencimento. Em harmonia com essa concepção, o Decreto $n^{\circ} 5.626$ (BRASIL, 2005) determinou aos surdos o direito de prioridade no acesso aos cursos de formação para docência da Libras, sendo representados na educação superior pela Licenciatura em Letras Libras e pelo curso de Pedagogia Bilíngue. Assim, em sua redação determina:

Art. $4^{\circ} \mathrm{A}$ formação de docentes para o ensino de Libras nas séries finais do ensino fundamental, no ensino médio e na educação superior deve ser realizada em nível superior, em curso de graduação de licenciatura plena em Letras: Libras ou em Letras: Libras/Língua Portuguesa como segunda língua.

Parágrafo único. As pessoas surdas terão prioridade nos cursos de formação previstos no caput. (BRASIL, 2005, p. 28, grifo nosso).

No entanto, além do cumprimento ao aludido decreto, as instituições federais de educação superior (Ifes) também têm o dever de reservar no mínimo 50\% das suas vagas para egressos de escolas públicas. Esse direito se sustenta por força da Lei $n^{\circ} 12.711$, a qual estabelece que essa reserva de vagas será distribuída para alunos com baixa condição socioeconômica e autodeclarados pretos, pardos e indígenas. Recentemente, esse documento legal foi alterado pela Lei $n^{0} 13.409$ (BRASIL, 2016), integrando a esse grupo também as pessoas com deficiência, nos seguintes termos:

\begin{abstract}
Art. $1^{\circ}$ As instituições federais de educação superior vinculadas ao Ministério da Educação reservarão, em cada concurso seletivo para ingresso nos cursos de graduação, por curso e turno, no mínimo $50 \%$ (cinquenta por cento) de suas vagas para estudantes que tenham cursado integralmente o ensino médio em escolas públicas.

Parágrafo único. No preenchimento das vagas de que trata o caput deste artigo, $50 \%$ (cinquenta por cento) deverão ser reservados aos estudantes oriundos de famílias com renda igual ou inferior a 1,5 salário-mínimo (um salário-mínimo e meio) per capita. [...]

Art. $3^{\circ} \mathrm{Em}$ cada instituição federal de ensino superior, as vagas de que trata o art. $1^{\circ}$ desta Le serão preenchidas, por curso e turno, por autodeclarados pretos, pardos e indígenas e por pessoas com deficiência, nos termos da legislação, em proporção ao total de vagas no mínimo igual à proporção respectiva de pretos, pardos, indígenas e pessoas com deficiência na população da unidade da Federação onde está instalada a instituição, segundo o último censo da Fundação Instituto Brasileiro de Geografia e Estatística - IBGE. (Redação dada pela Lei $n^{\circ}$ 13.409, de 2016).

Parágrafo único. No caso de não preenchimento das vagas segundo os critérios estabelecidos no caput deste artigo, aquelas remanescentes deverão ser completadas por estudantes que tenham cursado integralmente o ensino médio em escolas públicas (BRASIL, 2012).
\end{abstract}

Isso significa que, antecedendo à alteração da Lei $n^{\circ} 12.711$, ocorrida em 2016, as Ifes que ofertavam cursos de Letras Libras ou de Pedagogia Bilíngue já deviam obediência à determinação legal da prioridade aos surdos e à reserva de vagas para candidatos oriundos de escola pública, incluindo aqueles com baixa condição socioeconômica e/ou declarados pretos, pardos ou indígenas. 
Diante do exposto e ponderando que em nossa sociedade contemporânea o sujeito é constituído por múltiplas identidades, cumpre questionar: como as Ifes se organizaram para atender tal ordenamento jurídico e como abordaram a ocorrência de pluralidade de identidades de um único participante, por exemplo, surdo e negro ou surdo e indígena? Para responder a esses questionamentos, o presente artigo tem por objetivo investigar a efetivação do direito à prioridade atribuído aos surdos para ingresso em cursos de educação superior destinados à formação de professores de Libras.

Esta investigação ${ }^{3}$ foi guiada pelos pressupostos metodológicos da abordagem qualitativa, com a geração de registros feita a partir de uma pesquisa documental (SEVERINO, 2007). O corpus foi composto de 80 editais e 217 documentos anexos e complementares de processos seletivos realizados por $25^{4}$ Ifes para ingresso nos referidos cursos. Para isso, foi adotado como recorte o período de 2006 a $2015^{5}$, sendo o primeiro ano determinado pelo fato de ser o ano posterior à promulgação do Decreto $n^{\circ} 5.626$ e a data final por corresponder à finalização da pesquisa que deu origem a este artigo. Esse período permitiu uma análise longitudinal das implicações da política de ação afirmativa (PAA) desse decreto, cotejando essa mesma condição concernente à versão original da Lei $n^{\circ} 12.711$ (BRASIL, 2012).

Cumpre salientar que os documentos foram interpretados à luz da análise de conteúdo, em consonância ao postulado por Lüdke e André (1986) a respeito de esse ser o procedimento metodológico que, geralmente, melhor se adéqua à pesquisa documental. Assim, conforme esses autores, após um processo de (re)leitura do corpus, foram definidas as unidades de análise que permitiram a verificação da frequência e do contexto com que um tópico ou tema emergiu nos documentos. Na sequência, os dados foram tabulados para a construção de indicadores que respondessem aos objetivos da pesquisa, concatenando as evidências às orientações do quadro teórico.

A apresentação deste artigo foi organizada em quatro partes, composta pela seção introdutória, seguida da fundamentação teórica, da discussão dos resultados e, por fim, das considerações finais.

\footnotetext{
${ }^{3}$ Este artigo recupera resultados advindos da pesquisa de doutorado em educação intitulada "Acesso do surdo a cursos superiores de formação de professores de Libras em instituições federais" (KUMADA, 2016), conferindoIhes novas possibilidades analíticas, realizada sob orientação da Profa Dra Rosângela Gavioli Prieto.

${ }^{4}$ Essas 25 instituições consistiam a totalidade de Ifes registrada na plataforma do e-MEC até a data da consulta, em 06 de março de 2015, com oferta de cursos de licenciatura em Letras com habilitação em Libras e de Pedagogia Bilíngue.

${ }^{5}$ Desse modo, é válido ressaltar que na presente pesquisa não foi considerada a influência da alteração da Lei no 12.711, datada de 28 de dezembro de 2016 (BRASIL, 2016), a qual poderá ter seus efeitos passíveis de averiguação fora dos limites temporais dessa produção.
} 


\section{REFLETINDO ACERCA DAS IDENTIDADES SURDAS E DAS MÚLTIPLAS CONDIÇÕES DE DESVANTAGEM}

Para Hall $(1996,2000)$ e Woodward (2000), as identidades são constituídas historicamente por meio de práticas discursivas e estratégias enunciativas específicas vinculadas a um jogo de poder que marca a diferença entre a alteridade e a mesmidade. Assim, para existirem, as identidades dependem da marcação da diferença entre "quem é" e "quem não é" e isso pode ser contemplado pelo sistema de representações ou por formas de exclusão social. Basicamente, ao estabelecer a relação entre aquilo que somos, por exemplo, "sou brasileira", determinamos não apenas uma identidade própria, mas uma oposição ao outro quando dizemos "ela não é brasileira, ela é argentina". Isso cria uma interdependência contínua entre identidade e diferença, na qual a classificação simbólica de categorias cede espaço para o estabelecimento de uma ordem social na qual há os "locais" e os "forasteiros", ou seja, os que estão dentro e os que estão fora (WOODWARD, 2000, p. 46).

Nessa perspectiva, diferenças e identidades são fabricações da linguagem e não estão correlacionadas a nenhuma essência do que é ser homem, mulher, brasileiro, argentino, negro, branco, índio, surdo ou ouvinte, pois estas são construídas no universo linguístico discursivo das representações. Apesar disso, Woodward (2000) retrata sua preocupação, pois afirma que constantemente o corpo tem sido utilizado para estabelecer "verdades biológicas" a respeito de quem nós somos, servindo de fundamento para a determinação de identidades.

Ao pensarmos em identidades surdas com base nesses autores, negamos que haja um único marcador identitário (LOPES, 2011) para se definir quem é ou não surdo, evitando com isso o engessamento desse conceito em uma característica audiológica (ouvir ou não ouvir), linguística (saber ou não língua de sinais) ou cultural (conhecer ou não a cultura surda), entendendo que pode haver diferentes maneiras de se vivenciar as identidades surdas.

A pluralidade de identidades não é, contudo, uma característica restrita aos sujeitos surdos. Sendo as identidades culturalmente situadas e construídas por meio da linguagem, ao nos associarmos aos Estudos Culturais, assimilamos em Bhabha (2007), que o hibridismo é a origem e o resultado de todas as afirmações e sistemas culturais. Ainda nesse campo de estudos, coadunamo-nos a Hall $(1998,2000)$ e Fantini (2004), para quem a compreensão de identidades plurais está associada ao contexto da modernidade tardia em que estamos situados e que propõe a fragmentação das identidades do sujeito pós-moderno. Nesse sentido, ao falar de identidades surdas caberia nos empenhar para não os traduzir como se fossem somente "[...] surdos homens, brancos de classe média, que frequentam as instituições escolares, que fazem parte dos movimentos de resistência, que lutam pelos seus direitos linguísticos e de cidadania etc." (SKLIAR, 2016, p. 14). Para esse autor, a configuração do ser surdo integra, também, por exemplo, os surdos oriundos de classes populares, negros, mulheres e meninos de rua.

Em nossa sociedade contemporânea, nota-se, em diversas situações, a necessidade de negociação dessas múltiplas identidades, uma vez que um mesmo indivíduo pode apresentar mais de 
uma identidade de baixo prestígio social, ocupando, consequentemente, um local diferenciado nas relações de poder estabelecidas diante dos grupos hegemônicos. À vista disso, como lidar com a questão de indivíduos surdos que são, por exemplo, simultaneamente negros, pobres, mulheres e/ou homossexuais ${ }^{6}$ ? Será que a compreensão das múltiplas identidades tem sido considerada na organização dos processos seletivos envolvendo os cursos de graduação voltados à formação de professores de Libras? Sabe-se que sujeitos surdos e negros ou surdos e índios, por exemplo, carregam mais de uma condição de desvantagem social perante o grupo dominante, podendo sofrer o que Skliar (2016, p. 22) chamou de "dupla opressão"7.

Em nossa leitura, estar em uma dupla ou múltipla condição de discriminação é ocupar um espaço diferenciado e ainda não traduzido, que merece atenção redobrada por parte das políticas de identidade. Skliar (2003) declara que, por muito tempo, o grupo dos excluídos foi associado tão somente à pobreza, ou seja, os excluídos eram os pobres. Entretanto, tem sido observada uma subcategorização dessa exclusão que, além de ampliar essa lista (agregando imigrantes, refugiados, mulheres, índios, negros, pessoas com deficiência, população em situação de rua, viciados, homossexuais e transexuais, e outros) permitiu a vários sujeitos da sociedade contemporânea ter "[...] seu próprio fragmento e/ou parcela de exclusão [...]" (SKLIAR, 2003, p. 89). Evidentemente, a fragmentação das identidades pode ser vista como um modo de enfraquecimento das lutas instituídas pelas comunidades discriminadas (ou duplamente discriminadas), pois, aparentemente, geraria brechas pela luta do índio surdo, da índia surda, do homem surdo, da mulher surda, do negro surdo etc. No entanto, buscamos aqui, com efeito, problematizar a complexidade dessa constituição identitária deflagrada na pós-modernidade, a qual não se deve continuar homogeneizando e invisibilizando.

Para Castel (2011), ao sofrer de múltiplas desvantagens, a pessoa deve ser auxiliada diferenciadamente, pois apenas desse modo será capaz de superar esse contexto de exclusão e, portanto, o autor advoga em prol do que denomina de políticas de discriminação positiva, dentre as quais podemos enquadrar a PAA.

Segundo esse autor, existem duas formas de discriminação, uma positiva e outra negativa. Sob o ponto de vista da discriminação negativa, o sujeito é estigmatizado por uma característica que ele não escolheu, mas que o marca como portador de um defeito que o define sempre à margem da sociedade, agindo, portanto, como um mecanismo de exclusão. Por outro lado, a discriminação positiva consiste em "[...] fazer mais por aqueles que têm menos" (CASTEL, 2011, p. 13), por meio de "práticas suplementares" com intuito de (re)integrar a população discriminada ao regime comum.

\footnotetext{
${ }^{6}$ É válido relembrar que em nosso entendimento todas as identidades são híbridas e possuem diferentes modos de serem vivenciadas, ou seja, não há uma única forma de ser surdo, bem como de ser negro, homossexual, entre outras.

${ }^{7}$ A expressão é adotada por Skliar (2016) ao se referir a uma pesquisa relacionada a mulheres surdas e negras norte-americanas que encontravam maior dificuldade para ocupação profissional comparadas aos homens surdos e brancos.
} 
Assim, a discriminação positiva justificaria o tratamento diferenciado a determinados grupos que se encontram em desvantagem social, como uma estratégia de se igualar às condições de competição desses sujeitos em diferentes esferas da sociedade, tais como na escola, na universidade e no mercado de trabalho. Na mesma linha de raciocínio, ao discutir a proposta de uma escola justa, Dubet (2004) se apoia no princípio da discriminação positiva para entender os limites do ideal meritocrático tão apregoado e vinculado ao conceito de igualdade de oportunidades.

Segundo esse autor, a meritocracia consiste em dar (e exigir) a mesma coisa a (de) todos, tal como em uma competição, mas, para isso, deveria, inicialmente, garantir que os competidores dominem as regras do jogo e que o terreno seja igual para todos, incluindo juízes imparciais e sistemas transparentes, realidade ainda não sustentada pelo atual modelo escolar. Sob essa ótica, Dubet (2004, p. 546) assume que:

\footnotetext{
[...] em muitos casos a justiça consiste em ultrapassar a "igualdade pura". Se quisermos que as mulheres entrem na política, será preciso que criemos quotas; se desejarmos que [...] alunos dos bairros populares façam bons estudos, será preciso que tenham preparação específica; se quisermos que todos saibam ler, será preciso maior tempo de aprendizagem em algumas escolas; se quisermos que os alunos tenham acesso à alta cultura, será preciso organizar clubes de teatro e cinema para aqueles que têm apenas uma televisão em casa...
}

Logo, não haverá escola ou sociedade justa sem a adoção de medidas de discriminação positiva que equacionem as condições de desvantagem daqueles que têm sofrido com a discriminação negativa.

Tais condições justificam a prioridade na formação docente em Libras para candidatos(as) surdos(as) (BRASIL, 2005) e a reserva de vagas para estudantes egressos de escolas públicas, negros ou indígenas e com baixa condição econômica (BRASIL, 2012). Em concordância com Dhanda (2008, p. 52), seria como reconhecer que "[...] o duplamente discriminado deve ser duplamente compensado.". Entretanto, como dito anteriormente, não ignoramos que a implantação de medidas nesse âmbito pode gerar significativa polêmica, uma vez que, apesar do objetivo ser igualar as oportunidades, essas ações podem ser utilizadas para se acentuar as diferenças que produzem a discriminação negativa (SKLIAR, 2003; CASTEL, 2011).

Poderíamos aqui nos prolongar em justificar a reserva de vagas dada pela Lei $\mathrm{n}^{\circ} 12.711$ ou a questão da prioridade de acesso aos surdos estabelecida por meio do Decreto n० 5.626, contudo, nos associamos a Bobbio (1992) ao entender que se trata de uma ilusão acreditar que "[...] de tanto acumular e elaborar razões e argumentos - terminaremos por encontrar a razão e o argumento irresistível, ao qual ninguém poderá recusar a própria adesão.” (BOBBIO, 1992, p. 16). Na visão desse autor, os direitos são estabelecidos dentro de um momento histórico e de uma cultura, logo não existiriam argumentos ou fundamentos absolutos, ou seja, que seriam universalmente aceitos sem discordância. Para esse autor, os próprios direitos humanos não são direitos conquistados pelo simples fato de que somos humanos, mas são direitos históricos que refletem momentos vivenciados pela sociedade, resultados de uma série de movimentos sociais, históricos e políticos. É assim o direito de 
prioridade atribuído aos surdos no ingresso aos cursos de formação docente em Libras, consequência de uma intensa trajetória de lutas empreendidas pelas comunidades de pessoas surdas no país.

Dito de outra forma, a prioridade não precisa ser justificada, pois isso já foi feito anteriormente quando aprovada por intermédio do Decreto $n^{\circ}$ 5.626. Em consonância com Bobbio (1992), o que precisamos é garantir a exequibilidade desses direitos já reconhecidos pelo ordenamento jurídico, uma luta que, conforme sustenta o autor, não é menos laboriosa que a primeira. Em síntese, de acordo com Bobbio (1992, p. 23-24, grifo do autor): "O problema fundamental em relação aos direitos do homem, hoje, não é tanto o de justificá-los, mas o de protegê-los. Trata-se de um problema não filosófico, mas político."

Desse modo, passamos para a apreciação e discussão dos resultados gerados a partir da investigação com relação à efetivação das determinações subscritas no Decreto $n^{\circ} 5626$ e na Lei $n^{\circ}$ 12.711 .

\section{O RECONHECIMENTO DO SUJEITO MULTIFACETADO}

Inicialmente, faz-se mister contextualizar o contraste na implementação das normativas de cada documento legal. No bojo dos 80 editais de processos seletivos analisados, referente ao período de 2006 a 2015, 59 desses realizaram a reserva de vagas para a PAA da Lei $n^{0} 12.711$, sendo que algumas Ifes já registravam uma reserva percentual desde 2008 para estudantes de escola pública, autodeclarados negros ou indígenas, data anterior à referida determinação oficial. Assim, após a publicação da Lei $n^{\circ} 12.711$, foram encontrados apenas sete editais sem referência de cumprimento à PAA.

Em contrapartida, ao consultarmos a fruição do direito à prioridade no acesso dos candidatos surdos aos mesmos cursos de graduação para formação de professores de Libras, determinação que vigora desde 2005 e, portanto, há mais tempo que a supramencionada lei de 2012, obtivemos apenas 46 editais (o que indica 34 editais omissos à determinação da prioridade surda). Isto significa que, embora o Decreto $n^{\circ} 5.626$ seja sete anos mais antigo que a Lei $n^{\circ} 12.711$, houve menor obediência das Ifes ao decreto, o que desvela que a PAA para surdos apresentou menor eficácia comparada à PAA destinada aos sujeitos advindos da escola pública, negros, indígenas ou de baixa condição socioeconômica. Em nossa visão, esse contraste pode resultar da falta de clareza desse documento em identificar o que se entende por "prioridade".

Essa afirmação se sustenta ao analisarmos dentre os 46 editais que determinaram a prioridade aos surdos, que 31 utilizaram a reserva de um percentual do total de vagas, 13 atribuíram o que estamos denominando de critério de primazia e outros dois editais não discriminaram como seria operacionalizado esse direito. Cumpre esclarecer que, o termo primazia está sendo entendido no presente artigo como a condição na qual as vagas são, precipuamente, ofertadas para candidatos 
surdos e, acaso, não preenchidas são direcionadas aos ouvintes ${ }^{8}$. Nesse panorama, há ainda outro ponto de divergência que corrobora a falta de consenso na interpretação do Decreto $n^{\circ} 5.626$, visto que o percentual de reserva de vagas adotado por uma ou outra instituição também apresentou dissenso, com cotas que variavam de $10 \%$ até $80 \%$ das vagas destinada aos surdos, conforme ilustra o Gráfico 1.

Gráfico 1 - Percentual de reserva de vagas adotado pelos editais de processos seletivos para cursos de formação de professores de Libras - Brasil 2006 a 2015

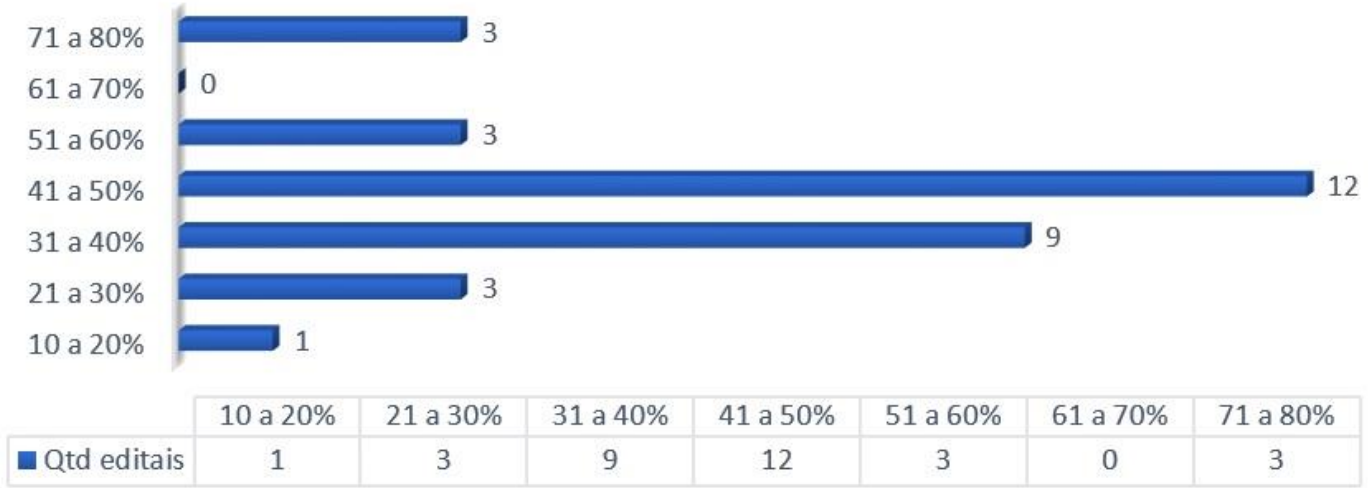

Fonte: Dados da pesquisa (KUMADA, 2016, p. 191).

Apesar de a maioria dos processos seletivos analisados concentrarem a reserva de vagas na faixa de $30 \%$ a $50 \%$, seria possível começar questionando a interpretação do conceito de "prioridade" da Ifes que reservou $10 \%$ das vagas para surdos. No caso, em 2013, ao determinar $10 \%$ das 50 vagas para surdos, uma das Ifes obteve 13 surdos inscritos, sendo oito deles classificados e, por fim, apenas cinco foram selecionados para o preenchimento integral da cota. Isso significa que apesar de terem sido classificados oito surdos, como a reserva para esse grupo era restrita a 10\%, apenas cinco foram admitidos pela referida instituição (KUMADA, 2016).

A nosso ver, esse dado se coaduna com a afirmação de Prieto (2000, p. 57) que, embora sem abordar os documentos legais aqui arrolados, destaca: "Muitas vezes, o conteúdo dos documentos oficiais é formulado com pouca precisão e/ou clareza, o que permite formas diversas de interpretação, podendo se constituir como um obstáculo para a adequada implantação e avaliação de políticas sociais." Assim, ao estabelecer a prioridade, mas não esmiuçar o que se entende com isso e como implementá-la, o Decreto $n^{\circ} 5.626$ abre brechas à inúmeras interpretações para esse conceito, por exemplo, como reserva de vagas ou como primazia. Diante do impasse, nota-se ainda a ausência de qualquer ação nesse âmbito, tal como constatamos em editais de diversas Ifes. Desse modo, dentre os 59 editais que adotaram a reserva de vagas em conformidade com a PAA da Lei no 12.711, verificamos que 28 atenderam somente a esta última, omitindo-se com relação à prioridade dos candidatos surdos,

\footnotetext{
8 De acordo com a nossa análise, observou-se que o critério de primazia apresentou maior êxito no preenchimento das vagas com candidatos surdos, enquanto o critério de reserva de vagas refletiu um menor índice de aprovação desses participantes (KUMADA, 2016).
} 
enquanto 31 documentos de editais cumpriram ambas as determinações legais, a saber, a Lei $n^{\circ}$ 12.711 e o Decreto $n^{\circ} 5.626$.

Desse montante de 31 editais decorreram dois movimentos. O primeiro em direção à admissão de um mesmo candidato acumular múltiplas condições de desvantagem social, permitindo durante a inscrição optar por mais de um grupo contemplado na reserva de vagas. O segundo, marcado pelo declínio da exigência de que os candidatos optassem por um ou outro grupo de reserva de vagas. Nesse sentido, foram 20 editais de nosso universo analisado que previram o cruzamento entre a prioridade para candidatos surdos e a reserva de vagas para a PAA da Lei no 12.711. Um exemplo pode ser conferido no Quadro 1 extraído do edital da Universidade Federal do Paraná (UFPR).

Quadro 1 - Distribuição das vagas do edital da UFPR (2014-2) para o processo seletivo de licenciatura em Letras Libras

\begin{tabular}{|c|c|c|c|c|c|c|c|c|}
\hline \multirow{4}{*}{ Categorias } & \multirow{4}{*}{$\begin{array}{c}\text { Total de } \\
\text { vagas }\end{array}$} & \multirow{4}{*}{$\begin{array}{c}\text { Concorrência } \\
\text { geral }\end{array}$} & \multirow{2}{*}{\multicolumn{6}{|c|}{$\begin{array}{c}\text { Distribuição das vagas conforme a Lei } 12.711 / 12 \text {, Decreto } n^{\circ} 7.824 / 12 \text { e Portaria } n^{\circ} \\
\text { 18/12-MEC } \\
\text { Candidatos que estudaram em Escola Pública }\end{array}$}} \\
\hline & & & & & & & & \\
\hline & & & \multicolumn{3}{|c|}{ Renda $<=1,5$ salários mínimo per capita } & \multicolumn{3}{|c|}{ Independente da renda } \\
\hline & & & $\begin{array}{c}\text { Total de } \\
\text { vagas }\end{array}$ & $\begin{array}{l}\text { Pretos, pardos e } \\
\text { indigenas } \\
(28,51 \%)\end{array}$ & $\begin{array}{c}\text { Demais } \\
\text { vagas }\end{array}$ & $\begin{array}{c}\text { Total de } \\
\text { vagas }\end{array}$ & $\begin{array}{l}\text { Pretos, pardos e } \\
\text { indigenas } \\
(28,51 \%)\end{array}$ & $\begin{array}{c}\text { Demais } \\
\text { vagas }\end{array}$ \\
\hline $\begin{array}{l}\text { Surdos } \\
\left(\text { Decreto } n^{\circ}\right. \\
5.626 / 2005)\end{array}$ & 22 & 13 & 5 & 2 & 3 & 4 & 2 & 2 \\
\hline Ouvintes & 8 & 4 & 2 & 1 & 1 & 2 & 1 & 1 \\
\hline
\end{tabular}

Fonte: Universidade Federal do Paraná (2014-2, p. 1).

O Quadro 1 evidencia que, para atender a Lei no 12.711 e o Decreto $n^{\circ}$ 5.626, a UFPR dividiu as vagas do curso de licenciatura em Letras Libras discriminando surdos e ouvintes, sendo $73 \%$ das vagas destinadas aos primeiros e $27 \%$ para ouvintes. A Ifes ainda subdividiu essas vagas entre concorrência geral e PAA, reservando 41\% (dos 73\%) para surdos que haviam estudado em escolas públicas, prevendo, dentre esse percentual, vagas específicas para candidatos autodeclarados pretos, pardos e indígenas e com renda inferior ou igual a um salário mínimo e meio per capita.

Por outro lado, um modo distinto de cumprimento da PAA e do direito de prioridade aos surdos foi desvelado por 11 editais. Como exemplo dessa organização, a Universidade Federal do Acre (Ufac), durante seu processo seletivo de 2013 explicita a proibição de o candidato se inscrever em mais de uma categoria, conforme pode ser acompanhado a seguir no excerto abaixo:

\subsection{O candidato deverá efetuar sua inscrição no Processo Seletivo Específico, indicando:}

a) o curso, dentre as opções oferecidas por este edital, para o qual deseja aprovação;

b) a modalidade de concorrência, dentre as opções abaixo: 
i) vagas reservadas em decorrência do disposto na Lei $n^{\circ}$ 12.711/12 (que trata da reserva de vagas para estudantes egressos do ensino médio de escolas públicas, critério de renda e étnico-racial);

ii) vagas destinadas a candidatos com deficiência;

iii) vagas destinadas à ampla concorrência.

iv) para o curso de Letras: Libras, vagas destinadas a candidatos surdos, aqueles cuja deficiente auditiva corresponda a perda bilateral, parcial ou total, de quarenta e um decibéis (dB) ou mais, aferida por audiograma nas frequências de $500 \mathrm{~Hz}, 1.000 \mathrm{~Hz}, 2.000 \mathrm{~Hz}$ e $3.000 \mathrm{~Hz}$.

c) É vedada ao estudante a inscrição em mais de um curso ou em mais de uma modalidade de concorrência para o mesmo curso. (UNIVERSIDADE FEDERAL DO ACRE, 2013-2, p. 1-2, grifo nosso).

Nota-se, que o veto da inscrição em mais de uma modalidade de concorrência significa dizer que surdos de camadas populares, oriundos de escolas públicas, autodeclarados pretos, pardos ou indígenas deveriam, nesses editais, optar por concorrer como surdos ou como egressos do ensino médio de escolas públicas (incluindo o critério de renda e/ou étnico-racial), ainda que atendessem a mais de uma modalidade. Diante dessa medida, cabe emprestar as palavras de Dhanda (2008, p. 51) e questionar se essa pode ser considerada melhor alternativa para "[...] tratar da vulnerabilidade daqueles que estão em desvantagem em mais de um parâmetro?".

Como dito anteriormente, a condição da múltipla desvantagem merece também atenção por parte de Castel (2011), ao advogar que em situações de minorias étnicas discriminadas simultaneamente pela raça e pela classe social são justificadas ações de discriminação positiva. Para justificar as políticas de discriminação positiva, o autor defende que quando o sujeito sofre de múltiplas desvantagens deve ser auxiliado diferenciadamente, pois só assim será capaz de superar o contexto de exclusão.

Para Boneti (2006, p. 189), que se respalda nos estudos desse autor, os excluídos são geralmente aqueles que "[...] acumulam a maior parte das desvantagens sociais: pobreza, falta de trabalho, sociabilidade restrita, condições precárias de moradia, grande exposição a todos os riscos de existência, etc." Cumpre destacar que, embora Castel (2011) e Boneti (2006) não retratem a convergência desses fatores com a deficiência ou com a surdez, autores como Skliar (2003) e Perez (2008) emprestam conceitos desse intelectual francês (CASTEL, 2011) para compreender a condição de exclusão no contexto da educação de surdos (SKLIAR, 2003) e das pessoas com deficiência (PEREZ, 2008), uma aproximação que também intentamos aqui.

A contribuição de Castel (2011) se assenta no reconhecimento da necessidade de políticas diferenciadas de discriminação positiva aos grupos que se encontram em duas ou mais condições de desvantagem social, tendo em vista que essa seria a única solução para equiparar as oportunidades e auxiliá-los a superar a situação na qual se encontram. Nessa lógica, consideramos que sujeitos surdos 
e negros, surdos e índios, surdos com baixas condições econômicas, entre outras combinações, deveriam ser considerados e duplamente contemplados.

Ademais, faz-se oportuno problematizar o conceito de identidade conforme postulado por Hall (1998), para quem o indivíduo pós-moderno não é constituído por uma, senão por várias identidades. O autor acredita que as identidades estão em colapso devido às mudanças estruturais pelas quais as sociedades modernas têm passado desde o final do século XX.

Sendo assim, essa discussão, leva-nos a compreender que as identidades surdas também participam da chamada "crise de identidades" citada por autores como Hall (1998) e Woodward (2000). Segundo Hall (1998), o sujeito unificado e as identidades fixas estão em declínio para dar lugar às novas identidades que têm fragmentado o indivíduo moderno. A partir desse raciocínio, acreditamos que essa deveria ser a perspectiva vislumbrada nos editais de vestibulares para formação de professores de Libras. Entendemos ainda que, por exemplo, a dificuldade de atender, simultaneamente, as exigências da Lei $n^{\circ} 12.711$ e do Decreto $n^{\circ} 5.626$, pode ser, em grande medida, decorrente dos desafios em se obter orientações aclaradas acerca da maneira mais adequada de garantir a prioridade para candidatos surdos e mesmo sobre o modo de promover o cruzamento dessas vagas com a PAA para egressos da escola pública (sob critérios de renda e autodeclaração como pretos, pardos e indígenas). Contudo, torna-se flagrante como essa questão merece maior atenção e debate, e deveria resultar em instrução complementar possivelmente no formato de um parecer, portaria ou outro tipo de manifestação do MEC ou de órgãos superiores que subsidiam as instituições de ensino superior a promover a igualdade de oportunidades aos sujeitos em múltiplas condições de desigualdade.

\section{CONSIDERAÇÕES FINAIS}

Ao investigar a efetivação do direito à prioridade atribuído às pessoas surdas no ingresso aos cursos superiores de formação docente em Libras a partir de uma análise ampliada do sujeito multifacetado, constatou-se que no período de 2006 a 2015 houve uma obediência menor, por parte das Ifes, às PAA destinadas aos surdos em relação às propostas para egressos da escola pública. Assim, embora o decreto que determina sobre o direito de prioridade date de 2005 e a lei que estabelece a reserva de vagas para estudantes advindos da escola pública tenha sido promulgada em 2012, no montante de 80 editais de processos seletivos analisados houve $42 \%$ desses que descumpriram a primeira normativa comparado à $26 \%$ que se omitiram diante da segunda. Ocorre que muitas Ifes já consideravam políticas diferenciadas para grupos de escolas públicas, autodeclarados negros ou indígenas antes da regulamentação legal em 2012. Esse dado pode desvelar ainda o tratamento diferenciado em relação a determinadas identidades.

Além disso, a pesquisa evidenciou o desafio de algumas Ifes em operacionalizar as PAA aos sujeitos que se encontram simultaneamente em múltiplas condições de desvantagens, ou seja, ao se identificarem, por exemplo, como surdos, oriundos da escola pública, pretos, pardos ou indígenas e 
sob critério de renda. Logo, apenas $25 \%$ dos editais analisados consideraram a constituição do sujeito a partir de múltiplas identidades, aceitando o tratamento diferenciado aos candidatos com mais de uma condição de desvantagem social.

Em suma, destaca-se que a existência de legislação não tem garantido a sua implantação universal, possivelmente em função de a própria normativa, no caso o Decreto no 5.626 , não estabelecer detalhamento sobre o direito previsto, neste caso a prioridade aos surdos.

Por fim, é importante enfatizar que, a nosso ver, a reserva de vagas para alunos da escola pública (incluindo o critério de renda e/ou étnico-racial) e o direito de prioridade para surdos no acesso à formação docente em Libras não devem se tornar medidas permanentes, pois, em consonância com Castel (2011), estas devem ser transitórias e de função propedêutica a fim de culminar em uma reforma mais ampla, sobretudo, na educação básica. Nessa direção, acreditamos que um primeiro passo para desencadear mudanças significativas nesse cenário, seria promover uma noção ampliada do conceito de identidades e, sobretudo das identidades surdas, favorecendo o reconhecimento do sujeito multifacetado e a ordem de seus direitos.

\section{REFERÊNCIAS}

1. BARNES, Colin. Discapacidad, política y pobreza en el contexto del "mundo mayoritario". Política y Sociedad, Madrid/Espanha, v. 47, n. 1, p. 11-25, 2010. Disponível em: <http://revistas.ucm.es/index.php/POSO/article/view/POSO1010130011A/21663>. Acesso em: 12 fev. 2018

2. BHABHA, HOMI K. O local da cultura. Tradução de Myriam Ávila, Eliana Lourenço de Lima Reis e Gláucia Renate Gonçalves. 4. ed. Belo Horizonte: Editora UFMG, 2007. 395 p.

3. BOBBIO, Norberto. A era dos direitos. Tradução de Carlos Nelson Coutinho. Rio de Janeiro: Campus, 1992. $271 \mathrm{p}$

4. BONETI, Lindomar Wessler. Exclusão e inclusão social - teoria e método. Contexto e Educação, ljuí, v. 21, n. 75 p. 187-206, jan./jun. 2006. http://dx.doi.org/10.21527/2179-1309.2006.75.187-206.

5. BRASIL. Decreto $n^{\circ} 5.626$, de 22 de dezembro de 2005. Regulamentada a Lei $n^{\circ} 10.436$, de 24 de abril de 2002, que dispõe sobre a Língua Brasileira de Sinais - Libras, e o art. 18 da Lei no 10.098, de dezembro de 2000. Diário Oficial da União, Brasília, DF, 23 dez. 2005. Seção 1, p. 28-30. Lei $n^{\circ}$ 10.436, de 24 de abril de 2002. Dispõe sobre a língua brasileira de sinais - Libras e dá outras providências. Diário Oficial da União, Brasília, DF, 25 abr. 2002. Seção 1, p. 23. 
Lei $n^{\circ} 12.711$, de 29 de agosto de 2012. Dispõe sobre o ingresso nas universidades federais e nas instituições federais de ensino técnico de nível médio e dá outras providências. Diário Oficial da União, Brasília, DF, 30 ago. 2012. Seção 1, p. 1-2.

8. 2012, para dispor sobre a reserva de vagas para pessoas com deficiência nos cursos técnico de nível médio e superior das instituições federais de ensino. Brasília, DF, 2016. Disponível em: <http://www.planalto.gov.br/ccivil_03/_ato2015-2018/2016/lei/L13409.htm>. Acesso em: 12 fev. 2018.

9. CANCLINI, Nestor Garcia. Culturas híbridas: estratégias para entrar e sair da modernidade. 4. ed. São Paulo: Edusp, 2003.

10. CASTEL, Robert. A discriminação negativa: cidadãos ou autóctones. Tradução de Francisco Morás. 2. ed. Petrópolis/RJ: Vozes, 2011. 136 p.

11. DHANDA, Amita. Construindo um novo léxico dos direitos humanos: convenção sobre os direitos das pessoas com deficiências. Revista Internacional de Direitos Humanos. São Paulo, v. 5, n. 8, p. 42-59, jun. 2008. http://dx.doi.org/10.1590/S1806-64452008000100003.

DUBET, François. O que é uma escola justa? Cadernos de Pesquisa, São Paulo, v. 34, n. 123, p. 539-555, 2004. Disponível em: <http://publicacoes.fcc.org.br/ojs/index.php/cp/article/view/4635/pdf>. Acesso em: 12 fev. 2018.

13. FANTINI, Marli. Águas turvas, identidades quebradas: hibridismo, heterogeneidade, mestiçagem \& outras misturas. In: ABDALA JUNIOR, Benjamin (Org.). Margens da cultura: mestiçagem, hibridismo \& outras misturas. São Paulo: Boitempo, 2004. p. 159-180.

14. FEDERAÇÃO NACIONAL DE EDUCAÇÃO E INTEGRAÇÃO DOS SURDOS. A educação que nós surdos queremos. Porto Alegre: Ufrgs, 1999.

15. GOULARTE, Ravele Bueno. Acesso e permanência no ensino superior: estratégias de governamento da conduta de alunos surdos incluídos. 2014. 107 f. Dissertação (Mestrado em Educação) - Centro de Educação, Universidade Federal de Santa Maria, Santa Maria, 2014.

16. HALL, Stuart. Who needs 'identity'? In: HALL, S \& du GAY, P. (Orgs.). Questions of Identity. London: Sage Publications, 1996. p. 1-17. Tadeu da Silva e Guacira Lopes Louro, 1998. 
Quem precisa de identidade? In: HALL, Stuart; WOODWARD, Kathryn; SILVA, Tomaz Tadeu da (Org.). Identidade e diferença: a perspectiva dos estudos culturais. Petrópolis: Vozes, 2000. p.103-133. (Série Educação pós-crítica).

19. KUMADA, Kate Mamhy Oliveira. Acesso do surdo a cursos superiores de formação de professores de Libras em instituições federais. 2016. 245 f. Tese (Doutorado em Educação) - Faculdade de Educação, Universidade de São Paulo, 2016.

KUMARAVADIVELU, B. A linguística aplicada na era da globalização. In: MOITA LOPES, Luiz Paulo da (Org.). Por uma linguística aplicada indisciplinar. São Paulo: Parábola, 2006. p. 129-147.

21. LOPES, Maura Corcini. Surdez \& Educação. 2. ed. Belo Horizonte: Autêntica, 2011. 102 p. (Coleção Temas e Educação, 5).

LÜDKE, Menga; ANDRÉ, Marli Elisa Dalmazo Afonso de. Pesquisa em educação: abordagens qualitativas. São Paulo: EPU, 1986. 99 p. (Temas Básicos de Educação e Ensino).

23. PEREZ, Maria Alice Rosmaninho. Educação especial em tempos de inclusão: política educacional e laços sociais. 2008. 164 f. Tese (Doutorado em Educação) - Faculdade de Educação, Universidade de São Paulo, São Paulo, 2008.

24. PRIETO, Rosângela Gavioli. Política educacional do município de São Paulo: estudo sobre o atendimento de alunos com necessidades educacionais especiais, no período de 1986 a 1996 . 2000. 260 f. Tese (Doutorado em Educação) - Faculdade de Educação, Universidade de São Paulo, São Paulo, 2000.

QUADROS, Ronice Müller de. Políticas linguísticas e educação de surdos em Santa Catarina: espaço de negociações. Cadernos Cedes, Campinas, v. 26, n. 69, p. 141-161, maio/ago. 2006. http://dx.doi.org/10.1590/S0101-32622006000200003.

26. SEVERINO, Antônio Joaquim. Metodologia do trabalho científico. 23. ed. São Paulo: Cortez, 2007. $304 \mathrm{p}$.

27. SKLIAR, Carlos. Pedagogia (improvável) da diferença: e se o outro não estivesse aí? Tradução de Giane Lessa. Rio de Janeiro: DP\&A, 2003. 224 p.

28. Um olhar sobre o nosso olhar acerca da surdez e das diferenças. In: SKLIAR, Carlos. (Org.). A surdez: um olhar sobre as diferenças. 8. ed. Porto Alegre: Mediação, 2016. p. 5-32. 
UNIVERSIDADE FEDERAL DO ACRE. Edital n. 02 (2013-2). Rio Branco: Ufac, 30 dez. 2013. 17 p. Disponível em: <http://www.ufac.br/portal/editais-concursos/prograd/edital-prograd-no-02-2014processo-seletivo-especifico-para-ingresso-nos-cursos-de-graduacao-de-letras-libras-licenciaturamusica-licenciatura-e-psicologiabacharelado/Edital_Processo_Seletivolibrasmsicaepsicologiaretificado.pdf>. Acesso em: 29 jun. 2016.

UNIVERSIDADE FEDERAL DO PARANÁ. Edital n. 23 (2014-2). Curitiba: UFPR, 27 out. 2014. 21 p. Disponível em: <http://www.nc.ufpr.br/concursos_institucionais/libras/2015/documentos/edital232014.pdf>. Acesso em: 25 jun. 2015.

31. WOODWARD, Kathryn. Identidade e diferença: uma introdução teórica e conceitual. In: HALL, Stuart; WOODWARD, Kathryn; SILVA, Tomaz Tadeu da (Orgs.). Identidade e diferença: a perspectiva dos estudos culturais. Petrópolis: Vozes, 2000. p. 7-72. (Série Educação pós-crítica).

\section{Kate Mamhy Oliveira Kumada}

Possui graduação em Pedagogia com habilitação em Educação Especial na área da Deficiência Auditiva pela Universidade Estadual Paulista Júlio de Mesquita Filho. Aprimoramento e Especialização em Surdez: desenvolvimento e inclusão pela Faculdade de Ciências Médicas da Universidade Estadual de Campinas, Especialização em Libras pela Faculdade Itaquá (2016), Mestrado em Linguística Aplicada pelo Instituto de Estudos da Linguagem pela Universidade Estadual de Campinas e Doutorado em Educação Especial pela Faculdade de Educação da Universidade de São Paulo. Atualmente é Professora Adjunta da Universidade Federal do ABC e membro do Projeto Tecnologias Assistivas para Surdos (TAS) desenvolvido na Universidade Estadual de Campinas.

\section{Rosângela Gavioli Prieto}

Graduada em Pedagogia, com habilitações em Educação do Deficiente pela Pontifícia Universidade Católica de Campinas e em Administração Escolar pela Universidade de Guarulhos; graduada em Psicologia pela Universidade de Guarulhos; mestre em Educação Especial (Educação do indivíduo especial) pela Universidade Federal de São Carlos; doutora em Educação pela Universidade de São Paulo. Atualmente, é professora da Faculdade de Educação da Universidade de São Paulo, onde foi chefe do Departamento de Administração Escolar e Economia da Educação; é coordenadora do Grupo de pesquisa CNPq Políticas de educação especial desde 2002; coordenou a Linha temática de pesquisa do Programa de Pós-graduação da Feusp. 


\section{Como citar este documento:}

KUMADA, Kate Mamhy Oliveira; PRIETO, Rosângela Gavioli. Formação superior de professores de libras: primeiros desafios ao reconhecimento do sujeito multifacetado. Reflexão e Ação, Santa Cruz do Sul, v. 27, n. 1, dez. 2018. ISSN 1982-9949. Disponível em: $<$ https://online.unisc.br/seer/index.php/reflex/article/view/11750>.

Acesso em: doi:https://doi.org/10.17058/rea.v27i1.11750. 